\title{
Training in the Japanese Society of Hepato-Biliary-Pancreatic Surgery board certification system for expert surgeons during 225 consecutive pancreaticoduodenectomies
}

\author{
Daisuke Hashimoto ${ }^{1,2}$, Takaomi Okawa ${ }^{2}$, and Fujio Matsumura ${ }^{2}$ \\ Department of Gastroenterological Surgery, ${ }^{1}$ Kumamoto University Graduate School of Medical Sciences, \\ Kumamoto, ${ }^{2}$ Omuta Tenryo Hospital, Omuta, Japan
}

\begin{abstract}
Backgrounds/Aims: A board certification system has been established by the Japanese Society of Hepato-BiliaryPancreatic Surgery (JSHBPS) for certifying surgeons who can perform high-level hepato-biliary-pancreatic surgeries safely. The aim of this study was to compare operative outcomes after pancreaticoduodenectomy performed by trainees, board-certified instructors, and expert surgeons of JSHBPS to determine the efficacy of education of trainees and operative safety. Methods: From 2009 to 2017, 225 consecutive patients underwent pancreaticoduodenectomy. Operations were performed by trainees, instructors, or JSHBPS experts. Clinical course and postoperative outcomes were retrospectively evaluated. Results: Twenty-two surgeons performed pancreaticoduodenectomy and two became expert surgeons. First, data of all patients who underwent pancreaticoduodenectomy $(n=225)$ were analyzed. Significantly shorter median operating time and less median operative bleeding were documented in the experts' group (428 min, $576 \mathrm{~g}$, respectively) than in the trainees' (498.5 min, $818 \mathrm{~g}$, respectively) and instructors' (557 min, $911 \mathrm{~g}$, respectively) groups. Morbidity did not differ significantly between the three groups. Second, data of patients who underwent simple pancreaticoduodenectomy $(n=130)$ were analyzed. Similarly, operating time was shorter and operative bleeding less in the experts' group. With increasing their experiences, intraoperative bleeding by 2 surgeons became the expert surgeons decreased. Conclusions: Surgeons judged experts by the JSHBPS board certification system achieve significantly shorter operating time and less operative bleeding during pancreaticoduodenectomy. In addition, PD performed by trainees has an acceptable incidence of postoperative complications. This is the first report which indicated the efficacy of education toward being the JSHPBS board-certified expert surgeon. (Ann Hepatobiliary Pancreat Surg 2019;23:145-154)
\end{abstract}

Key Words: Pancreaticoduodenectomy; Complication; Education

\section{INTRODUCTION}

In Japan, operative mortality rates after pancreaticoduodenectomy (PD) remain from $2 \%$ to $3 \% .^{1-3}$ In addition, despite recent advances in surgical techniques, interventional radiology, and perioperative intensive care support, morbidity rates remain high, ranging from $30 \%$ to $40 \%$. Thus, PD remains one of the most complex procedures in gastroenterological surgery. ${ }^{6}$

It was recently reported that improvement in short-term outcomes after PD is associated with higher PD volume in pancreatic centers. ${ }^{7,8}$ In addition, surgeon experience remains an important determinant of overall morbidity. ${ }^{7-9}$
Despite the availability of a training curriculum and simulation system for trainees, hands-on intraoperative experience remains one of the most important components of a surgeon's training. ${ }^{10}$ Patients may express reservations if they know that a trainee is to perform their operation. Thus, it has been a challenge for surgeons in teaching hospitals to balance their obligations to their patients with their duty of training the next generation of surgeons.

A board certification system has been established in 2008 by the Japanese Society of Hepato-Biliary-Pancreatic Surgery (JSHBPS) for certifying surgeons who can perform high-level hepato-biliary-pancreatic (HBP) surgeries safely. $^{2}$ In this certification system, board-certified in-

Received: June 29, 2018; Revised: November 29, 2018; Accepted: December 14, 2018

Corresponding author: Daisuke Hashimoto

Department of Gastroenterological Surgery, Kumamoto University Graduate School of Medical Sciences, 1-1-1 Honjo, Kumamoto 860-8556, Japan Tel: +81-96-373-5213, Fax: +81-96-371-4378, E-mail: daisukeh007@gmail.com

Copyright (C) 2019 by The Korean Association of Hepato-Biliary-Pancreatic Surgery

This is an Open Access article distributed under the terms of the Creative Commons Attribution Non-Commercial License (http://creativecommons.org/ licenses/by-nc/4.0) which permits unrestricted non-commercial use, distribution, and reproduction in any medium, provided the original work is properly cited. Annals of Hepato-Biliary-Pancreatic Surgery • pISSN: 2508-5778 - eISSN: 2508-5859 
structors and board-certified expert surgeons are recognized on the basis of defined requirements, such as experience in performing a specified number of high-level HBP surgeries as an operator. ${ }^{2}$ As of today, there are 779 boardcertified instructors and 222 board certified expert surgeons of JSHPBS in the entire Japan. ${ }^{2}$ However, no previous studies have evaluated the process of training toward being a board-certified expert surgeon or compared the operative outcomes achieved by trainees, board-certified instructors, and board-certified expert surgeons of JSHBPS.

The aim of this study was to compare the short-term outcomes of PDs by trainees with those of board-certified surgeons (board-certified instructors and board-certified expert surgeons of the JSHPBS) to determine the efficacy of education of trainees and operative safety.

\section{MATERIALS AND METHODS}

\section{Patients and data collection}

This was a retrospective cohort study of 225 consecutive patients who had undergone PD at the Department of Gastroenterological Surgery of Kumamoto University Hospital, a board-certified training institution of JSHPBS between 2009 and 2017. Each patient provided written informed consent prior to surgery. All procedures in this study met the guidelines of the Declaration of Helsinki. The study was approved by the Institutional Review Board of Kumamoto University Hospital (\#1120).

Patients were managed perioperatively as previously described. ${ }^{11-13}$ Postoperative complications were assessed according to the Clavien-Dindo scale. ${ }^{14}$ Postoperative pancreatic fistulas (POPFs) were defined according to the International Study Group for Pancreatic Surgery. ${ }^{15}$ Operative and postoperative data were collected and stored in an electronic database.

\section{Surgical procedure for PD and treatment of postoperative complication}

Patients with malignant tumor underwent D2 lymph node dissection. ${ }^{16-19}$ When the superior mesenteric and portal veins were involved, they were resected and reconstructed. The pancreas was severed with a surgical scalpel. For reconstruction, the cut end of jejunum was moved up retrocolically. A reconstruction was performed by a modified Child's methods. One or two peritoneal drainage tubes (6.3-mm closed drains) were placed. Abdominal complications such as POPF, abdominal abscess and post-pancreatectomy hemorrhage were usually treated by ongoing drainage, ultrasonography-guided or computed tomographyguided drainage, or surgical intervention. However, when those measures failed to control these complications, reoperation was performed promptly before patients developed more severe complications such as sepsis or shock. In this study, the board certified surgeon of the Japan Surgical Society (JSS) qualified a trainee to perform PD as an operator. ${ }^{20}$ Certification of the board-certified surgeon of JSS has provided the foundations for board-certified surgeon systems of subspecialty surgical societies. ${ }^{20}$ The trainees performed PD as an operator under appropriate supervision by a scrubbed senior surgeon as the first assistant.

\section{Board certification of instructors of JSHPBS}

The system for board certification of instructors was introduced by JSHPBS in 2008. Thus, this study includes patients who underwent PD from 2009. To qualify as a board-certified instructor, applicants must have performed 100 or more high-level HBP surgeries as an operator or teaching first assistant (Fig. 1A). ${ }^{2}$ This instructor certification program concluded in 2014. No surgeon whose certificate-grade has been changed from trainee to board certified instructor was included in this study.

\section{Board certification of expert surgeons of JSHPBS}

A system for board certification of expert surgeons by JSHPBS began in 2011. To achieve board-certified expert surgeon status, applicants have to perform 50 or more high-level HBP surgeries as an operator at a board-certified training institution while training (Fig. 1A). ${ }^{2}$ In addition, applicants must archive the defined training program and earn the required number of credits. Finally, the applicants have to submit a video of specific surgery for assessment of their surgical skills by JSHBPS and pass an evaluation by anonymous referees. Trainees in HBP surgery in Kumamoto University Hospital generally go through training toward board-certified expert surgeon. A trainee can become directly board-certified expert surgeon without being a period of instructor in this certification system (Fig. 1A). When a surgeon's certificate-grade changed 
A

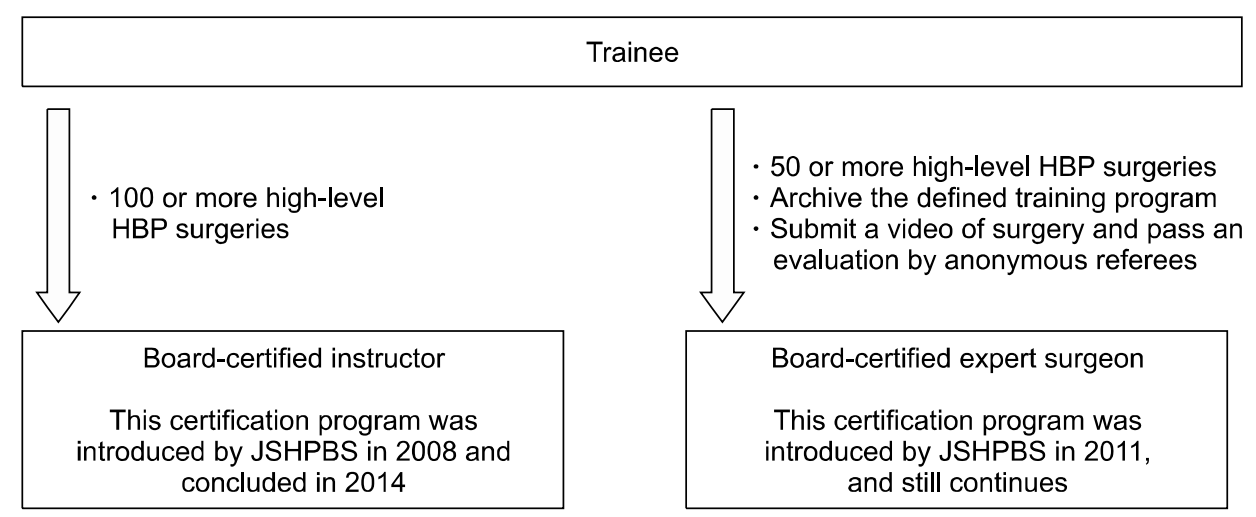

B

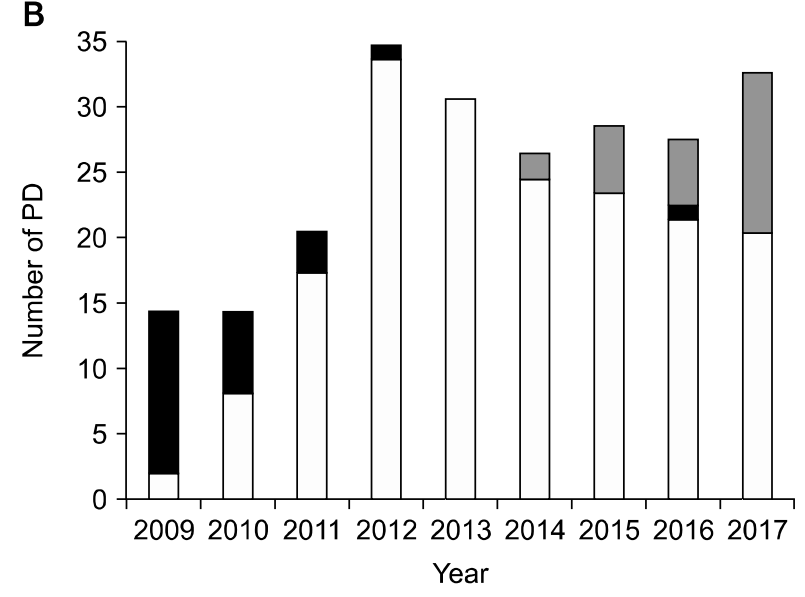

from trainee to board certified expert, patients who were operated by the surgeon before certificate were included in the trainee group, and patients who were operated by the surgeon after certificate were included in the boardcertified expert surgeon group.

\section{Statistical analysis}

Descriptive statistics are presented as median (range) or number (percentage), as appropriate. Data were analyzed using SAS software (version 9.1; SAS Institute, Cary, NC, USA). Parameters were compared between patient subgroups using Student t-test, Mann-Whitney $U$ test, $\chi^{2}$ test or ANOVA. Continuous variables were analyzed using Pearson's correlation test. $p<0.05$ was considered to denote statistical significance.
By board-certified instructors By board-certified expert surgeons

By trainees
Fig. 1. Board-certification system of the JSHPBS (A) and numbers of $\mathrm{PD}$ procedures per year (B). HBP, hepato-biliarypancreatic; JSHPBS, Japanese Society of Hepato-Biliary-Pancreatic Surgery.

\section{RESULTS}

Number of PDs and operators (trainee, boardcertified instructors, and board-certified expert surgeons)

The number of PDs performed per year from 2009 to 2017 are shown in Fig. 1B. This number has generally been increasing. In this series, 22 surgeons performed PDs as an operator. The median number of PDs per operator during the whole study period was 4.5 (1-72). Two trainees became board-certified expert surgeons in 2016 and 2014, respectively (Fig. 1B). PDs performed by board-certified instructors have been decreasing (Fig. 1B), because they had tended to participate in the operation as a supervisor, but not as an operator, and transferred to another hospital.

\section{Characteristics of all patients who had under- gone PD}

Firstly, operative results of all patients who had undergone PD were analyzed (Fig. 2). Of the 225 consecutive 

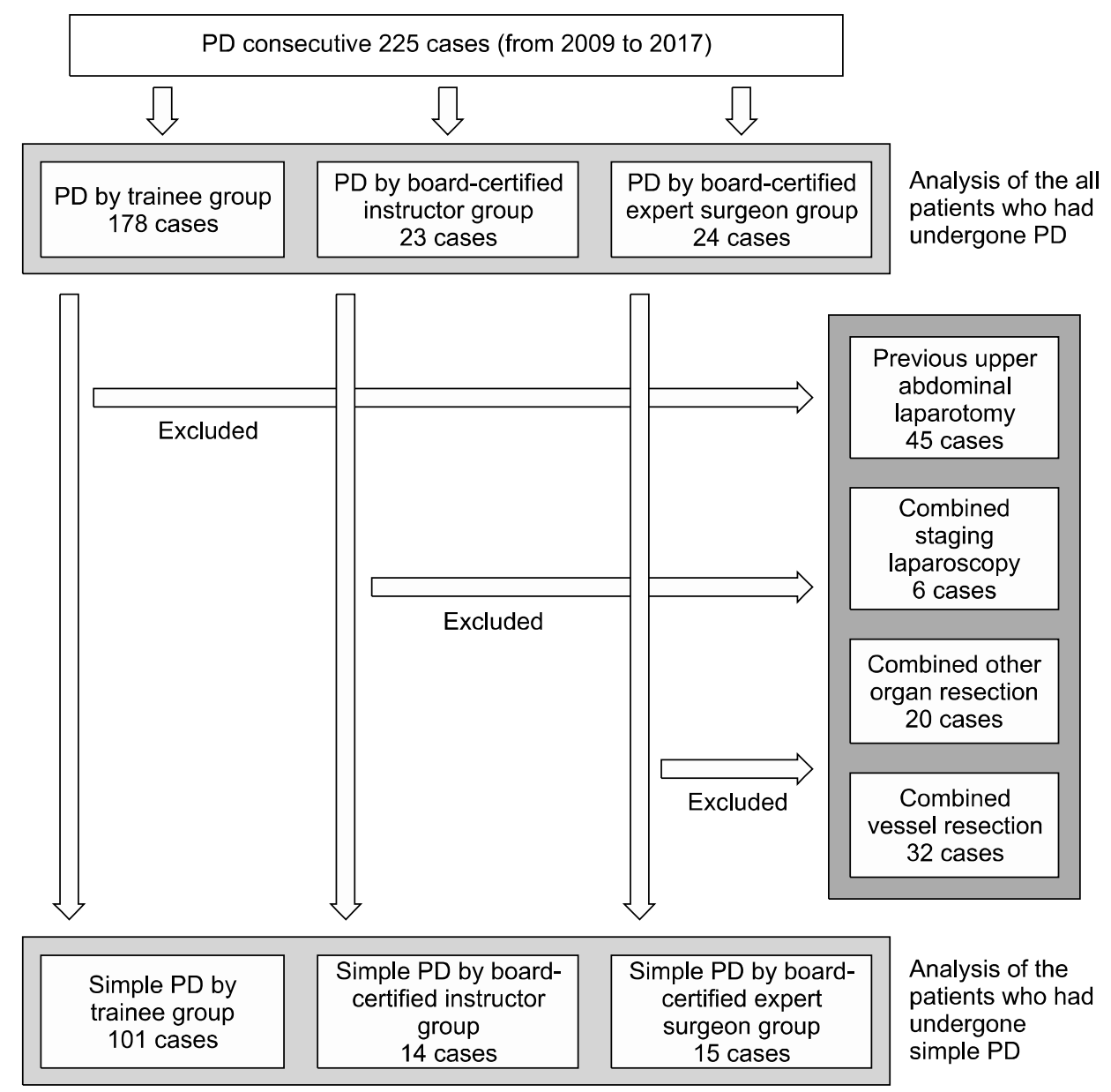

Fig. 2. Patient flow diagram.

patients who had undergone PD during the study period, 178 were operated on by trainees, 23 by board-certified instructors, and 24 by board-certified expert surgeons (Fig. 2). Table 1 shows relevant clinical and other characteristics of these patients. There were no significant differences in age, sex, or body mass index (BMI) between the groups. The distribution of performance status was also similar in the three groups, as were the rates of prior laparotomy and preoperative bile duct drainage. There were no significant differences in comorbidities (diabetes mellitus, ischemic heart disease, and respiratory disease). The most common diagnosis was pancreatic cancer in all groups (37.1\%, 52.2\%, and 58.3\%, respectively).

\section{Operative findings and postoperative outcomes of all patients who had undergone PD}

Intraoperative variables and outcomes of all patients who underwent PD are shown in Table 2. Operating times were significantly shorter in the expert surgeon group (423 min, range, 339-722 $\mathrm{min}$ ) than in the trainee (498.5 min, range, 268-864 $\mathrm{min}$ ) and instructor groups (557 $\mathrm{min}$, range, 438-936 min). Median operative bleeding was significantly less in the expert surgeon group (576 g, range, $77-1485 \mathrm{~g}$ ) than in the trainee (818 g, range, 77-6378 g) and instructor groups (911 g, range, 337-13153 g). The incidence of intraoperative blood transfusion was significantly lower in the expert $(12.5 \%)$ than in the trainee $(37.0 \%)$ and instructor groups $(56.5 \%)$. Combined staging laparoscopy was performed on only one patient (4.3\%), who was in the instructor group. There were no significant differences between the groups in the incidence of combined vessel resection and reconstruction or combined other organ resection (Table 2). The rates of soft pancreatic texture did not differ significantly, being $57.3 \%$ patients in the trainee group, $47.8 \%$ in the instructor group, and $54.2 \%$ in the expert group.

There was no significant difference in the incidence of postoperative Clavien-Dindo > III complications between the trainee $(33.1 \%)$, instructor $(26.1 \%)$, and expert (16.7\%) groups (Table 2). The most common complication was 
Table 1. Characteristics of all patients who underwent PD

\begin{tabular}{|c|c|c|c|c|}
\hline & Trainee group $(\mathrm{n}=178)$ & $\begin{array}{l}\text { Board-certified } \\
\text { instructor group }(n=23)\end{array}$ & $\begin{array}{l}\text { Board-certified expert } \\
\text { surgeon group }(n=24)\end{array}$ & $p$-value \\
\hline Male:female, $\mathrm{n}$ & $113: 65$ & $13: 10$ & $17: 6$ & 0.642 \\
\hline Median age (range), years & $67.5(18-85)$ & $66(37-87)$ & $68(53-86)$ & 0.200 \\
\hline Performance status $(0: 1: 2), \mathrm{n}$ & $135: 42: 1$ & $15: 7: 1$ & $16: 6: 1$ & 0.918 \\
\hline Median body mass index (range), $\mathrm{kg} / \mathrm{m}^{2}$ & $22.0(15.6-35.8)$ & $23.0(16.0-28.8)$ & $22.0(17.8-31.2)$ & 0.321 \\
\hline Previous laparotomy, n (\%) & $36(20.2)$ & $4(17.4)$ & $5(20.8)$ & 0.986 \\
\hline Preoperative bile duct drainage, $\mathrm{n}(\%)$ & $72(40.4)$ & $9(39.1)$ & $8(33.3)$ & 0.572 \\
\hline \multicolumn{5}{|l|}{ Comorbidities, n (\%) } \\
\hline Diabetes mellitus & $46(26.0)$ & $5(21.7)$ & $5(20.8)$ & 0.948 \\
\hline Ischemic heart disease & $13(7.3)$ & $1(4.3)$ & $3(12.5)$ & 0.853 \\
\hline Respiratory disease & $21(11.8)$ & $2(8.7)$ & $3(12.5)$ & 0.979 \\
\hline \multicolumn{5}{|l|}{ Final diagnosis, $\mathrm{n}(\%)$} \\
\hline Pancreatic cancer & $66(37.1)$ & $12(52.2)$ & $14(58.3)$ & 0.992 \\
\hline Bile duct cancer & $42(23.6)$ & $6(26.1)$ & $4(18.2)$ & \\
\hline NET & $21(11.8)$ & 0 & $2(9.1)$ & \\
\hline Vater's papilla cancer & $19(10.7)$ & $3(13.0)$ & $2(9.1)$ & \\
\hline IPMN & $15(8.4)$ & $2(8.7)$ & $2(9.1)$ & \\
\hline Duodenal cancer & $4(2.2)$ & 0 & 0 & \\
\hline Metastasis from other organs & $3(1.7)$ & 0 & 0 & \\
\hline Chronic pancreatitis & $3(1.7)$ & 0 & 0 & \\
\hline GIST & $2(1.1)$ & 0 & 0 & \\
\hline Gall bladder cancer & $2(1.1)$ & 0 & 0 & \\
\hline SPT & $1(0.6)$ & 0 & 0 & \\
\hline
\end{tabular}

GIST, gastrointestinal stromal tumor; IPMN, intraductal papillary mucinous neoplasm; NET, neuroendocrine tumor; SPT, solid pseudopapillary tumor

Grade B or C POPF $(21.3 \%$ in the trainee group, $17.4 \%$ in the instructor group, and $8.3 \%$ in the expert group). Median postoperative hospital stay did not differ significantly between the trainee (16 days; range, 11-101 days), instructor (20 days; range, 13-53 days) and expert (18 days; range, 12-47 days) groups. There was no 30-day mortality in any group. Only one patient died within 90 days after operation, that patient was in the trainee group; however, that difference is not significant.

\section{Characteristics of patients who had undergone simple PD}

Secondly, to evaluate the quality of PD itself free of any effects of additional procedures, patients who had previously undergone upper abdominal laparotomy (45) or undergone combined staging laparoscopy (6), combined other organ resection (20), or combined vessel resection (32) were excluded from the analysis. Thus, operative results of the patients who underwent simple PD only were analyzed separately (Fig. 2). Of the 130 patients who had undergone simple PD, 101 were operated on by trainees,
14 by board-certified instructors, and 15 by board-certified expert surgeons (Fig. 2). Table 3 shows clinical and other relevant characteristics of these patients. There were no significant differences in age, sex, and BMI between the groups. The distribution of performance status was also similar in the three groups. There were no significant differences in comorbidities (diabetes mellitus, ischemic heart disease, and respiratory disease). The most common diagnosis was pancreatic cancer in all groups (39.6\%, $35.7 \%$, and $40.0 \%$, respectively).

\section{Operative findings and postoperative outcomes of patients who had undergone simple PD}

Intraoperative variables and outcome of patients who had undergone simple PD are shown in Table 4. Operating times were significantly shorter in the expert surgeon group (400 $\mathrm{min}$, range, 339-616 $\mathrm{min}$ ) than in the trainee (472 min, range, 268-834 $\mathrm{min}$ ) and instructor groups (529 min, range, 453-724 min). Median operative bleeding was significantly less in the expert surgeon group (528 g, range, $123-849 \mathrm{~g}$ ) than in the trainee (734 g, range, 77- 
Table 2. Operative findings and postoperative outcomes of all patients who had undergone PD

\begin{tabular}{|c|c|c|c|c|}
\hline & $\begin{array}{c}\text { Trainee } \\
\text { group }(n=178)\end{array}$ & $\begin{array}{l}\text { Board-certified } \\
\text { instructor group }(n=23)\end{array}$ & $\begin{array}{l}\text { Board-certified expert } \\
\text { surgeon group }(n=24)\end{array}$ & $p$-value \\
\hline Median (range) operation time, min & $498.5(268-864)$ & $557(438-936)$ & $423(339-722)$ & 0.0003 \\
\hline Median (range) intraoperative bleeding, $g$ & $818(77-6378)$ & $911(337-13153)$ & $576(77-1485)$ & 0.006 \\
\hline $\begin{array}{l}\text { Incidence of intraoperative blood trans- } \\
\text { fusions, } \mathrm{n}(\%)\end{array}$ & $66(37.0)$ & $13(56.5)$ & $3(12.5)$ & 0.028 \\
\hline Combined staging laparoscopy, n (\%) & $5(2.8)$ & $1(4.3)$ & 0 & 0.164 \\
\hline \multicolumn{5}{|l|}{$\begin{array}{l}\text { Combined vessel resection and reconstru- } \\
\text { ction, } \mathrm{n}(\%)\end{array}$} \\
\hline Hepatic artery & $1(0.6)$ & $1(4.3)$ & $2(8.3)$ & 0.972 \\
\hline SMV-PV & $22(12.3)$ & $4(17.4)$ & $4(16.7)$ & 0.924 \\
\hline \multicolumn{5}{|l|}{ Combined other organ resection, $\mathrm{n}(\%)$} \\
\hline Liver & $6(3.4)$ & $1(4.3)$ & $2(8.3)$ & 0.820 \\
\hline Digestive tract & $4(2.8)$ & $1(4.3)$ & $1(4.2)$ & 0.973 \\
\hline Others & $4(2.8)$ & 0 & $1(4.2)$ & 0.967 \\
\hline Pancreatic texture (soft:hard) & $102: 76$ & $11: 12$ & $13: 11$ & 0.813 \\
\hline Morbidity (Clavien-Dindo > III), n (\%) & $59(33.1)$ & $6(26.1)$ & $4(16.7)$ & 0.355 \\
\hline Grade $\mathrm{B}$ or $\mathrm{C}$ POPF & $38(21.3)$ & $4(17.4)$ & $2(8.3)$ & 0.464 \\
\hline Abdominal abscess & $15(8.4)$ & $1(4.3)$ & $2(8.3)$ & 0.917 \\
\hline Abdominal hemorrhage & $8(4.5)$ & 0 & 0 & 0.777 \\
\hline Bile leakage & $3(1.7)$ & $1(4.3)$ & 0 & 0.966 \\
\hline Venous thrombosis & $2(1.1)$ & 0 & 0 & 0.662 \\
\hline Delayed gastric empting & $1(0.6)$ & 0 & 0 & 0.210 \\
\hline Pneumoniae & $1(0.6)$ & 0 & 0 & 0.210 \\
\hline Renal failure & $1(0.6)$ & 0 & 0 & 0.210 \\
\hline Re-laparotomy for complication, n (\%) & $17(9.6)$ & $1(4.3)$ & 0 & 0.489 \\
\hline $\begin{array}{l}\text { Median (range) postoperative hospital stay, } \\
\text { days }\end{array}$ & $16(11-101)$ & $20(13-53)$ & $18(12-47)$ & 0.619 \\
\hline 30-day mortality, n (\%) & 0 & 0 & 0 & - \\
\hline 90-day mortality, n (\%) & $1(0.6)$ & 0 & 0 & 0.210 \\
\hline
\end{tabular}

*One patient did not undergo pancreaticodigestive anastomosis because of an atrophic pancreatic remnant

POPF, postoperative pancreatic fistula; SMV-PV, superior mesenteric and portal vein

$3202 \mathrm{~g}$ ) and instructor groups (769 g, range, 442-3309 g). Intraoperative blood transfusion was required in $25.7 \%$ in the trainee group and $57.1 \%$ in the instructor group. On the other hand, it was not required in the expert group $(0 \%)$ and the difference of the incidence was significant. The rates of soft pancreatic textures were not significantly different: $55.4 \%$ of patients in the trainee group, $50 \%$ in the instructor group, and $60.0 \%$ in the expert group.

There was no significant difference in the incidence of postoperative Clavien-Dindo > III complications between the trainee $(29.7 \%)$, instructor $(21.4 \%)$, and expert (13.3\%) groups. The most common complication was grade B or C POPF $(18.8 \%$ in the trainee group, $14.3 \%$ in the instructor group, and $6.7 \%$ in the expert group). There was also no significant difference in re-laparotomy for complications, which was not necessary in the instructor or expert groups, but did occur in the trainee group (7.9\%).
Median postoperative hospital stay did not differ significantly between the trainee (16 days; range, 11-101 days), instructor (19 days; range, 13-35 days) and expert (16 days; range, 12-41 days) groups. There was no 30-day or 90-day mortality in any group.

\section{Intraoperative bleeding and operation time in procedures performed by operators who became board-certified expert surgeons}

Fig. 3 shows the amount of intraoperative bleeding in chronological order of procedures performed by two operators, who became board-certified expert surgeons during the study period (Fig. 1B). With increasing experience, the amount of intraoperative bleeding decreased significantly in both operator's procedure, respectively. Fig. 4 shows the operation time in chronological order of procedures performed by same operators. The operation time 
Table 3. Characteristics of patients who had undergone simple PD

\begin{tabular}{|c|c|c|c|c|}
\hline & $\begin{array}{c}\text { Trainee } \\
\text { group }(n=101)\end{array}$ & $\begin{array}{l}\text { Board-certified } \\
\text { instructor group }(n=14)\end{array}$ & $\begin{array}{l}\text { Board-certified expert } \\
\text { surgeon group }(n=15)\end{array}$ & $p$-value \\
\hline Male:female, $\mathrm{n}$ & $68: 33$ & $8: 6$ & $10: 5$ & 0.878 \\
\hline Median age (range), years & $67(18-85)$ & $76(59-87)$ & $68(55-80)$ & 0.064 \\
\hline Performance status $(0: 1: 2), \mathrm{n}$ & $72: 28: 1$ & $8: 5: 1$ & $11: 3: 1$ & 0.931 \\
\hline Median body mass index (range), $\mathrm{kg} / \mathrm{m}^{2}$ & $21.6(15.6-35.8)$ & $23.0(18.2-28.8)$ & $22.4(19.0-31.2)$ & 0.091 \\
\hline Preoperative bile duct drainage, n (\%) & $39(38.6)$ & $5(35.7)$ & $6(40.0)$ & 0.985 \\
\hline \multicolumn{5}{|l|}{ Comorbidities, n (\%) } \\
\hline Diabetes mellitus & $28(27.7)$ & $4(28.6)$ & $3(20.0)$ & 0.937 \\
\hline Ischemic heart disease & $7(6.9)$ & $1(7.1)$ & $1(6.7)$ & 0.778 \\
\hline Respiratory disease & $10(9.9)$ & $2(14.3)$ & $1(6.7)$ & 0.987 \\
\hline \multicolumn{5}{|l|}{ Final diagnosis, n (\%) } \\
\hline Pancreatic cancer & $40(39.6)$ & $5(35.7)$ & $6(40.0)$ & 0.858 \\
\hline Bile duct cancer & $24(23.8)$ & $5(35.7)$ & $4(26.7)$ & \\
\hline Vater's papilla cancer & $13(12.9)$ & $2(14.3)$ & $2(13.3)$ & \\
\hline IPMN & $11(10.9)$ & $2(14.3)$ & $2(13.3)$ & \\
\hline NET & $8(7.9)$ & 0 & $1(6.7)$ & \\
\hline Duodenal cancer & $2(2.0)$ & 0 & 0 & \\
\hline Chronic pancreatitis & $1(1.0)$ & 0 & 0 & \\
\hline GIST & $1(1.0)$ & 0 & 0 & \\
\hline SPT & $1(1.0)$ & 0 & 0 & \\
\hline
\end{tabular}

GIST, gastrointestinal stromal tumor; IPMN, intraductal papillary mucinous neoplasm; NET, neuroendocrine tumor; SPT, solid pseudopapillary tumor

Table 4. Operative findings and postoperative outcomes of patients who had undergone simple PD

\begin{tabular}{|c|c|c|c|c|}
\hline & $\begin{array}{c}\text { Trainee } \\
\text { group }(n=101)\end{array}$ & $\begin{array}{l}\text { Board-certified } \\
\text { instructor group }(n=14)\end{array}$ & $\begin{array}{l}\text { Board-certified expert } \\
\text { surgeon group }(n=15)\end{array}$ & $p$-value \\
\hline Median (range) operation time, $\min$ & $472(268-834)$ & $529(453-724)$ & $400(339-616)$ & 0.0009 \\
\hline Median (range) intraoperative bleeding, $\mathrm{g}$ & $734(77-3202)$ & $769(442-3309)$ & $528(123-849)$ & 0.014 \\
\hline $\begin{array}{l}\text { Incidence of intraoperative blood trans- } \\
\text { fusions, } \mathrm{n}(\%)\end{array}$ & $26(25.7)$ & $8(57.1)$ & 0 & 0.013 \\
\hline Pancreatic texture (soft:hard) & $56: 45$ & $7: 7$ & $9: 6$ & 0.962 \\
\hline $\begin{array}{l}\text { Morbidity } \\
\text { (Clavien-Dindo > III), n (\%) }\end{array}$ & $30(29.7)$ & $3(21.4)$ & $2(13.3)$ & 0.485 \\
\hline Grade $\mathrm{B}$ or $\mathrm{C}$ POPF & $19(18.8)$ & $2(14.3)$ & $1(6.7)$ & 0.719 \\
\hline Abdominal abscess & $6(5.9)$ & $1(7.1)$ & $1(6.7)$ & 0.826 \\
\hline Abdominal hemorrhage & $5(5.0)$ & 0 & 0 & 0.944 \\
\hline Bile leakage & $2(2.0)$ & 0 & 0 & 0.704 \\
\hline Venous thrombosis & $1(1.0)$ & 0 & 0 & 0.243 \\
\hline Delayed gastric empting & $1(1.0)$ & 0 & 0 & 0.243 \\
\hline Pneumoniae & $1(1.0)$ & 0 & 0 & 0.243 \\
\hline Renal failure & $1(1.0)$ & 0 & 0 & 0.243 \\
\hline Re-laparotomy for complication, n (\%) & $8(7.9)$ & 0 & 0 & 0.722 \\
\hline $\begin{array}{l}\text { Median (range) postoperative hospital stay, } \\
\text { days }\end{array}$ & $16(11-101)$ & $19(13-50)$ & $16(12-41)$ & 0.476 \\
\hline 30-day mortality, n (\%) & 0 & 0 & 0 & - \\
\hline 90-day mortality, n (\%) & 0 & 0 & 0 & - \\
\hline
\end{tabular}

* One patient did not undergo pancreaticodigestive anastomosis because of an atrophic pancreatic remnant POPF, postoperative pancreatic fistula; SMV-PV, superior mesenteric and portal vein 

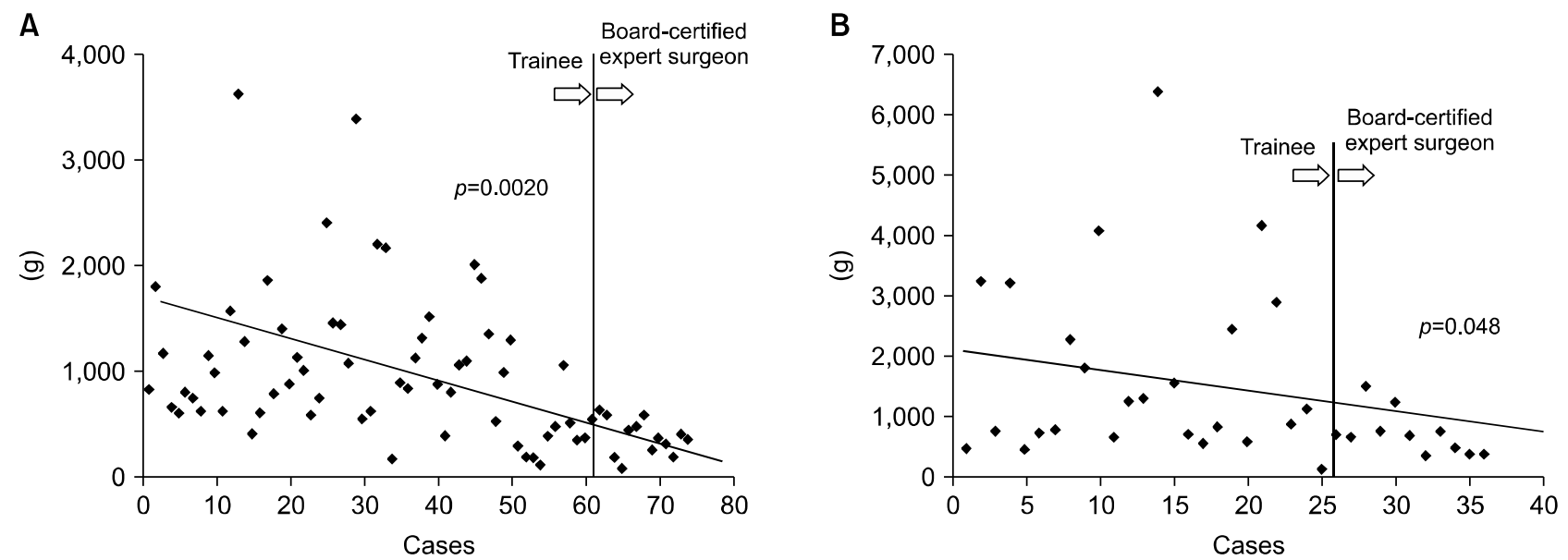

Fig. 3. Intraoperative bleeding in chronological order of procedures performed by Operators A (A) and B (B) who became board-certified expert surgeons.
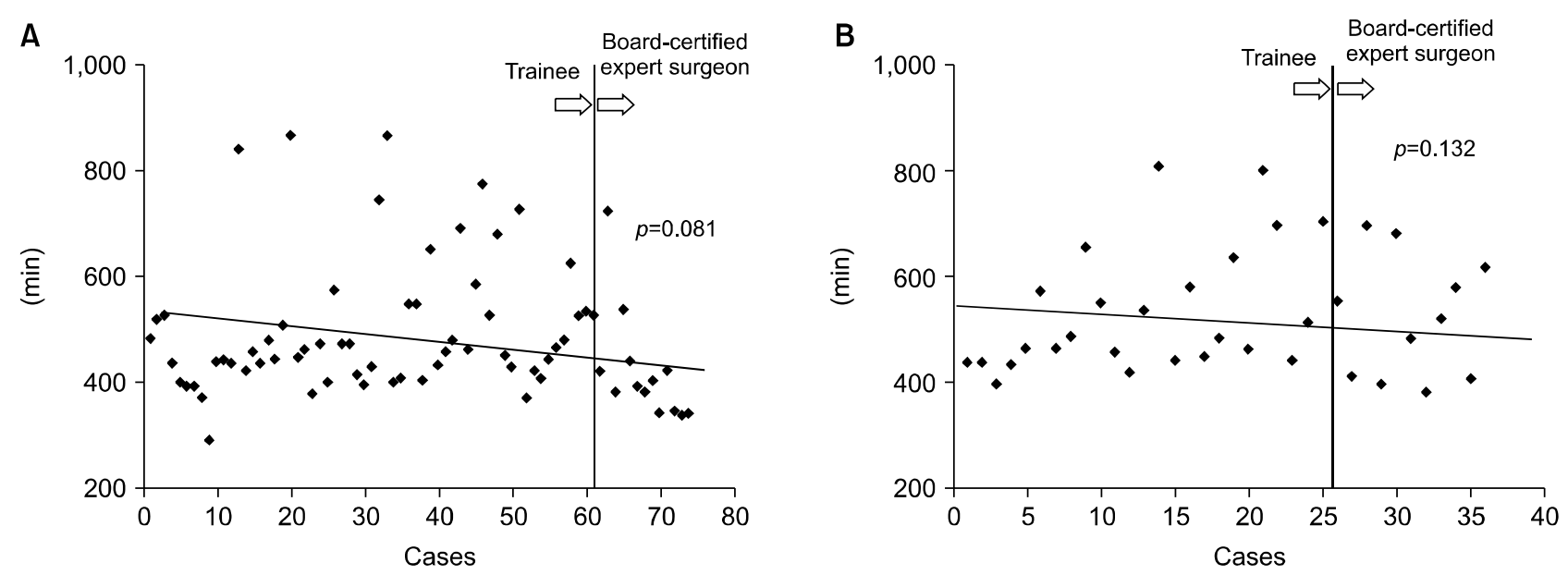

Fig. 4. Operation time in chronological order of procedures performed by Operators A (A) and B (B) who became board-certified expert surgeons.

decreased with increasing experience in both operators, however, the tendencies were not significant.

\section{DISCUSSION}

Recently reported mortality rates after PD have decreased in high-volume centers, ${ }^{2}$ however, in several nation-wide studies perioperative mortality was higher than anticipated. ${ }^{1,21}$ In other words, perioperative risk after PD remains high. Previous reports comparing postoperative outcomes after PD between high- and low-volume centers have demonstrated an association between the number of surgical cases per year and surgical outcomes. ${ }^{7,8,21}$

The relationship between operative outcomes after PD and each surgeon's experience and appropriate education for trainee remains under discussion. Birkmeyer et al. ${ }^{22}$ have reported that the individual surgeon's experience of performing PD is inversely associated with operative mortality. Tseng et al. ${ }^{23}$ compared post-PD outcomes between the first and the next 60 such procedures performed by each surgeon and showed that some outcomes of the next 60 procedure improved; namely, blood loss, operation time, hospital stay and margin status. Relles et al. ${ }^{9}$ demonstrated that the surgical experience of resident surgeons affect surgical outcomes of PD. In contrast, Shirai et al. ${ }^{10}$ recently reported that PD performed by junior surgeons requires longer operating times but can be performed safely on appropriately selected patients with intraoperative supervision and perioperative management. One possible reason for this discrepancy is lack of agreement on defi- 
nitions of junior and senior surgeons.

Otsubo et al. $^{2}$ recently investigated safety-related outcomes of hepatobiliary pancreatic surgeries performed at board-certified training institutions after establishment of the JSHBPS board certification system for expert surgeons. They reported 30-day and 90-day mortality rates after PD of $0.5 \%$ and $1.2 \%$, respectively, and that the JSHBPS board certification system for expert surgeons has significantly decreased mortality subsequent to high-level HBP surgeries such as hepatic trisectionectomy. ${ }^{2}$ However, no previous study has evaluated the process of training to become a board-certified expert surgeon or compared the operative outcomes of trainees, board-certified instructors, and board-certified expert surgeons.

In this study, we found significantly shorter operating times and less intraoperative bleeding in the expert group than in the trainee and instructor groups for all patients in this series of 225 consecutive PD s. Because this cohort included various complicated cases, patients who had undergone simple PD cases were analyzed separately. Similarly, operating times were shorter and operative bleeding less in the expert group in this subgroup. In addition, intraoperative bleeding in procedures performed by the surgeons who became expert surgeons during the study period decreased with increasing experience. Thus, this study is the first to suggest that the training system for becoming a board-certified expert surgeon of the JSHBPS has reduced operating time and operative bleeding for PD. There was only one 90-day mortality in the trainee group, and none in the instructor group and the expert group. However, the deference of mortality was not significant. In addition, the morbidity rate after PD did not improve significantly in the instructor group and the expert group compared with the trainee group. Considered from a different angle, morbidity rates were not increased in the trainee group. It confirmed appropriate management of operative safety and education of trainees by intraoperative supervision and perioperative management. ${ }^{10}$

This study had some limitations. First, the number of patients operated on by instructors and experts may have been too small to draw definite conclusions from our findings. As of today, there are only 222 board certified expert surgeons and 225 board-certified training institutions of JSHPBS in the entire Japan. ${ }^{2}$ Thus, each boardcertified training institution has few board certified expert surgeons at present. Further prospective multicenter studies or propensity score matched analysis with more patients should be designed. Second, when a trainee performs $\mathrm{PD}$ as an operator, a supervisor occasionally performs some difficult parts of the operation, such as hemostasis, dissection around major blood vessels, or pancreaticodigestive anastomosis in the presence of a soft pancreas, rather than the trainee. In this study, we could not investigate this possible bias. Third, the operation time in chronological order of procedures performed by operators who became board-certified expert surgeons did not decrease, perhaps because the operation time was directly affected by the difficulty of each case and combined procedures, such as other organ resection.

In conclusion, training toward becoming a JSHBPS board-certified expert surgeon is associated with reduced operating time and intraoperative bleeding during PD. In addition, PD performed by trainees with appropriate supervision has an acceptable incidence of postoperative complications. This is the first report which indicated the efficacy of education toward being the board-certified expert surgeon.

\section{ACKNOWLEDGEMENTS}

We thank Dr Trish Reynolds, MBBS, FRACP, from Edanz Group (www.edanzediting.com/ac) for editing a draft of this manuscript.

\section{REFERENCES}

1. Kimura W, Miyata H, Gotoh M, Hirai I, Kenjo A, Kitagawa Y, et al. A pancreaticoduodenectomy risk model derived from 8575 cases from a national single-race population (Japanese) using a web-based data entry system: the 30-day and in-hospital mortality rates for pancreaticoduodenectomy. Ann Surg 2014;259:773780 .

2. Otsubo T, Kobayashi S, Sano K, Misawa T, Ota T, Katagiri S, et al. Safety-related outcomes of the Japanese Society of HepatoBiliary-Pancreatic Surgery board certification system for expert surgeons. J Hepatobiliary Pancreat Sci 2017;24:252-261.

3. Aoki S, Miyata H, Konno H, Gotoh M, Motoi F, Kumamaru $\mathrm{H}$, et al. Risk factors of serious postoperative complications after pancreaticoduodenectomy and risk calculators for predicting postoperative complications: a nationwide study of 17,564 patients in Japan. J Hepatobiliary Pancreat Sci 2017;24:243-251.

4. Sugiura T, Mizuno T, Okamura Y, Ito T, Yamamoto Y, Kawamura I, et al. Impact of bacterial contamination of the abdominal cavity during pancreaticoduodenectomy on surgical-site infection. Br J Surg 2015;102:1561-1566.

5. Hashimoto D, Chikamoto A, Ohmuraya M, Hirota M, Baba H. 
Pancreaticodigestive anastomosis and the postoperative management strategies to prevent postoperative pancreatic fistula formation after pancreaticoduodenectomy. Surg Today 2014;44:12071213.

6. Hirono S, Murakami Y, Tani M, Kawai M, Okada K, Uemura $\mathrm{K}$, et al. Identification of risk factors for pancreatic exocrine insufficiency after pancreaticoduodenectomy using a 13C-labeled mixed triglyceride breath test. World J Surg 2015;39:516-525.

7. Wood TW, Ross SB, Bowman TA, Smart A, Ryan CE, Sadowitz $\mathrm{B}$, et al. High-volume hospitals with high-volume and low-volume surgeons: is there a "field effect" for pancreaticoduodenectomy? Am Surg 2016;82:407-411.

8. Schmidt CM, Turrini O, Parikh P, House MG, Zyromski NJ, Nakeeb A, et al. Effect of hospital volume, surgeon experience, and surgeon volume on patient outcomes after pancreaticoduodenectomy: a single-institution experience. Arch Surg 2010;145: 634-640.

9. Relles DM, Burkhart RA, Pucci MJ, Sendecki J, Tholey R, Drueding R, et al. Does resident experience affect outcomes in complex abdominal surgery? Pancreaticoduodenectomy as an example. J Gastrointest Surg 2014;18:279-285; discussion 285.

10. Shirai Y, Shiba H, Horiuchi T, Saito N, Furukawa K, Sakamoto $\mathrm{T}$, et al. Assessment of outcome after pancreaticoduodenectomy by junior surgeons. Anticancer Res 2016;36:3505-3510.

11. Hashimoto D, Takamori H, Sakamoto Y, Ikuta Y, Nakahara O, Furuhashi $\mathrm{S}$, et al. Is an estimation of physiologic ability and surgical stress able to predict operative morbidity after pancreaticoduodenectomy? J Hepatobiliary Pancreat Sci 2010;17: 132-138.

12. Hashimoto D, Chikamoto A, Arima K, Taki K, Inoue R, Imai $\mathrm{K}$, et al. Unused sterile instruments for closure prevent wound surgical site infection after pancreatic surgery. J Surg Res 2016; 205:38-42.

13. Hashimoto D, Nakagawa S, Umezaki N, Yamao T, Kitano Y, Yamamura K, et al. Efficacy and safety of postoperative anticoagulation prophylaxis with enoxaparin in patients undergoing pancreatic surgery: a prospective trial and literature review. Pancreatology 2017;17:464-470.

14. DeOliveira ML, Winter JM, Schafer M, Cunningham SC, Cameron $\mathrm{JL}$, Yeo CJ, et al. Assessment of complications after pancreatic surgery: a novel grading system applied to 633 patients undergoing pancreaticoduodenectomy. Ann Surg 2006;244:931-937; discussion 937-939.

15. Bassi C, Marchegiani G, Dervenis C, Sarr M, Abu Hilal M, Adham M, et al. The 2016 update of the International Study Group (ISGPS) definition and grading of postoperative pancreatic fistula: 11 years after. Surgery 2017;161:584-591.

16. Japan Pancreas Society, ed. General rules for the study of pancreatic cancer. 6th ed. Osaka: Japan Pancreas Society, 2009.

17. Japanese Society of Biliary Surgery Society, ed. General rules for surgical and pathological studies on cancer of the biliary tract. 5th ed. Japanese Society of Biliary Surgery Society, 2003.

18. Japan Pancreas Society, ed. General rules for the study of pancreatic cancer. 7th ed. Osaka: Japan Pancreas Society, 2009.

19. Miyazaki M, Ohtsuka M, Miyakawa S, Nagino M, Yamamoto M, Kokudo N, et al. Classification of biliary tract cancers established by the Japanese Society of Hepato-Biliary-Pancreatic Surgery: 3(rd) english edition. J Hepatobiliary Pancreat Sci 2015;22: 181-196.

20. Ito Y. Surgical education and postgraduate training in Japan. World J Surg 2008;32:2134-2137.

21. Krautz C, Nimptsch U, Weber GF, Mansky T, Grützmann R. Effect of hospital volume on in-hospital morbidity and mortality following pancreatic surgery in Germany. Ann Surg 2018;267: 411-417.

22. Birkmeyer JD, Stukel TA, Siewers AE, Goodney PP, Wennberg DE, Lucas FL. Surgeon volume and operative mortality in the United States. N Engl J Med 2003;349:2117-2127.

23. Tseng JF, Pisters PW, Lee JE, Wang H, Gomez HF, Sun CC, et al. The learning curve in pancreatic surgery. Surgery 2007; 141:694-701. 